\title{
3D MODELLING TOWARDS STRATA REGISTRATION
}

\author{
Mohd Nizar Hashim*, Muhammad Imzan Hassan, Alias Abdul Rahman \\ 3D GIS Research lab, Faculty of Built Environment and Surveying, Universiti Teknologi Malaysia (UTM) \\ *mnhpiko@gmail.com,imzan@utm.my, alias@utm.my
}

KEY WORDS: 3D registration, 3D strata, 3D model

\begin{abstract}
:
The rapid development of a country has resulted in limited land use. This is indirectly encouraging multilayer development (strata) especially for the development of residential properties such as condominiums, apartments and others. The idea of having 3D database for the cadastral system has been discussed for a good and efficient management in Malaysia. The development in 3D GIS will make a 3D cadastral realizable. In Malaysia, the current 2D cadastre system is regularly updated by the National Mapping Agency (NMA) and Land Offices (LO). However, this 2D information may not be able to serve complex situations. The 3D strata acquisition and 3D modelling are important for strata title to manage the Right, Restriction and Responsibility (RRRs). This means needs to the system extended into 3D cadastre environment. One of the data acquisition techniques is utilizing LiDAR data to solve the problem. 3D geospatial objects could be generated from the captured points cloud. The NMA attempts to make use of LiDAR datasets for strata registration purposes. This paper also discuss the needs the 3D strata registration via XML and IndoorGML for future 3D strata development in Malaysia.
\end{abstract}

\section{INTRODUCTION}

Strata title is a form of ownership designed for multi-level apartment blocks and horizontal subdivisions with shared areas. As been stated in National Land Code (1965) - Malayan land code, the 'strata' term refers to building that have more than two levels. The urbanization has led to the development and change of patterns in property ownerships. Higher rise buildings have been built which offers different types of property ownerships other than landed property (Mohd Noh, 2012). As the existing have more than one level and each level has many lots. Thus, the need for strata title is increasing. The situations lead to the introduction of the Strata Titles Act 1985 (Nasorudin, 2016). Rapid growth in data acquisition technology, such as indoor LiDAR creates an opportunity for 3D strata modelling (Isa et. al, 2018). The technology produces high density and accurate 3D point clouds. 3D representation provides clearer definition of the juridical situation of the property within the multilayer reality as it corresponds to reality better than the traditional 2D presentation (Chong, 2006). Moreover, ability to display 3D representation allows better tools for examining, analysing and extracting especially in right, restriction and responsibility (RRRs).

Section 2 discusses on the current strata registration and management. Strata data acquisition techniques discuss in section 3. Section 4 describes the needs of 3D model for strata registration. Conclusion and future work will be discussed in section 5 .

\section{STRATA MANAGEMENT}

The situation of rapid growth of urbanization in Malaysia demands better strata management for high rise buildings (unit ownerships) as reported by several researchers including Hassan, 2017 and Zulkifli et. al, 2014.

\subsection{Right}

It is a formal or informal entitlement to own, to do something, or to refrain from doing something. The examples that related to the right of ownership are freehold and leasehold property. A freehold can be defined as the entitlement to hold a property with a perpetual right. There is no limit of time to hold the property. A freehold property lies with the title holder until they transfer it of their own accord. The owner has the right to use the property for any purposes however in accordance with the local regulations. Freehold property is inheritable and there are no restrictions on the right of the property owner to further transfer the property. As for leasehold, it can be defined as the right to hold or use the property for a fixed period of time at a given price, without transfer of ownership, on the basis of a lease contract (Pirounakis, 2013). Leasehold is a fixed asset. Every lease or sub-lease must exceed three years. The maximum period of a lease is ninety-nine years for the whole land and thirty years for a part only of the land. Right also involve with the selling or renting out the lot parcel. If the issuance of the strata title is still pending, the owner of a unit can still sell or assign their unit and the unavailability of the strata title does not in any way affect the owner's right to their unit.

\subsection{Restriction}

It is a formal or informal entitlement to refrain from doing something. An example is caveat. Once a caveat is lodged on the register document of title, it restricts the lot from recording any dealing affecting the estate or the interest claimed caveat category. The meaning here is when a property have a caveat titles, the owner is restrict to sell, pawn or lease the land or any interest until the transfer dealings caveat is automatically withdrawn or expired (including to Malaysian land law).

One type of caveat is private caveat. A caveat of this type can be registered by anyone with regard to the interests of the ownership of the property, though it is not his own. An example is the person who has made a partial payment of the deposit for the purchase or lease agreement who have registered on the land. However, this does not preclude private caveat of affairs other than those applicable to the title as a specific endorsement. Private caveat would be cancelled automatically after six years. Other example of restriction is on strata title. An 
owner cannot renovate his lot without permission of the responsible party. An owner cannot put suspension outside of his lot parcel which this situation is really happens for example in Kuala Lumpur. The lot parcel owner hangs their clothes outside of their lot parcel which worsened the views. This situation happens when there is no a standard restriction made to handle it.

\subsection{Responsibility}

It is a formal or informal obligation to do something. Each land owner need to pay for the land tax annually to PTG while the owner who own residential houses, shops, business property, companies, hotels and all premises established in the local authority area needs to pay assessment tax twice a year.

Besides, for the lot owners of strata building they need to pay monthly charges for the maintenance of the common areas and other contributions to the developer. This is important for the developer to state the responsibility for each lot parcel owner to pay the amount of the monthly charges and what are the services provided.

The description of parcel boundaries currently practiced involves the process of converting cadastral survey data into graphical information. It commences with the preparation of the survey plan that would be subsequently be submitted for authentication by the survey authority, after approval of which could be termed as Certified Plan (CP).

Information shown in CP currently includes the technical data that is of interest to both the land surveyors as well as land owners. Primarily the document will portrays the bearings, distances and the 2D coordinates of two extreme boundary points. In Strata Titles Act 1985 (AHS), the boundary of strata parcel will falls in the center of the wall. The owner of the strata parcel is restrict to make additions or renovation involving areas that are outside of the boundary walls.

\subsection{RRR on strata}

Right on strata is major part to counter the Party-wall issues, the centre line of the wall can be derived from two edges of the point cloud surface (Isa et. al, 2018). Other example is the right of a lot parcel owner to accessory parcel such as corridor, lift, swimming pool, and gym. Basically, the lot parcel owners have the right on the accessory parcel but tied to the responsible in using it.

\subsection{Current registration}

Generally the registration processes begin with an application from property owner to the Department Land and Mines or Land Office (LO). The application requires a complete plan of unit measurement (measured by surveyor and verified by national mapping agency), approved strata title by LO. Figure 1 illustrates the standard flow for strata tittle registration.

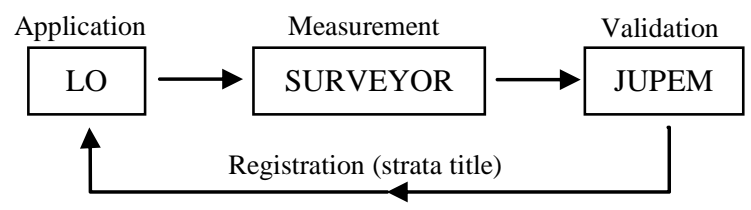

Figure 1. Standard flow for strata title registration
Detail process for strata registration can be referred to PKPUP Circular, volume 1/2015.

\section{STRATA DATA ACQUISITION TECHNIQUES}

Laser technology is being used to scan the surface of objects in order to analyse shapes and their appearances. The collected data could be used to construct digital model either in twodimensional (2D) or three-dimensional (3D) models. In order to generate $3 \mathrm{D}$ strata model, there are two possible capturing methods namely Terrestrial Laser Scanning (TLS) and Indoor Mobile Laser Scanning (MLS). Both of these methods have advantages and disadvantages for the 3D modelling (Isa et. al, 2018). Figure 2 shows the LiDAR types for data acquisition.

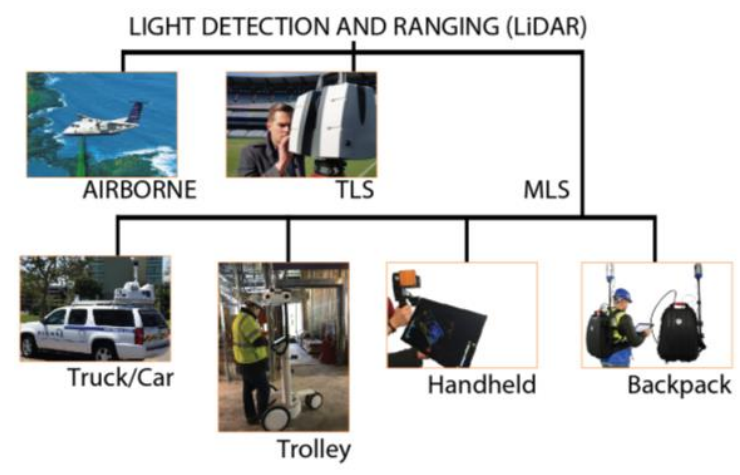

Figure 2. LiDAR types for data acquisition.

\section{NEEDS OF 3D MODEL FOR STRATA REGISTRATION}

3D strata data acquisition and 3D modelling is different from $2 \mathrm{D}$ cadastral practise. For example the 3D model contains more details such as edges and surface. Figure 3 shows the transformation from point cloud to 3D model.
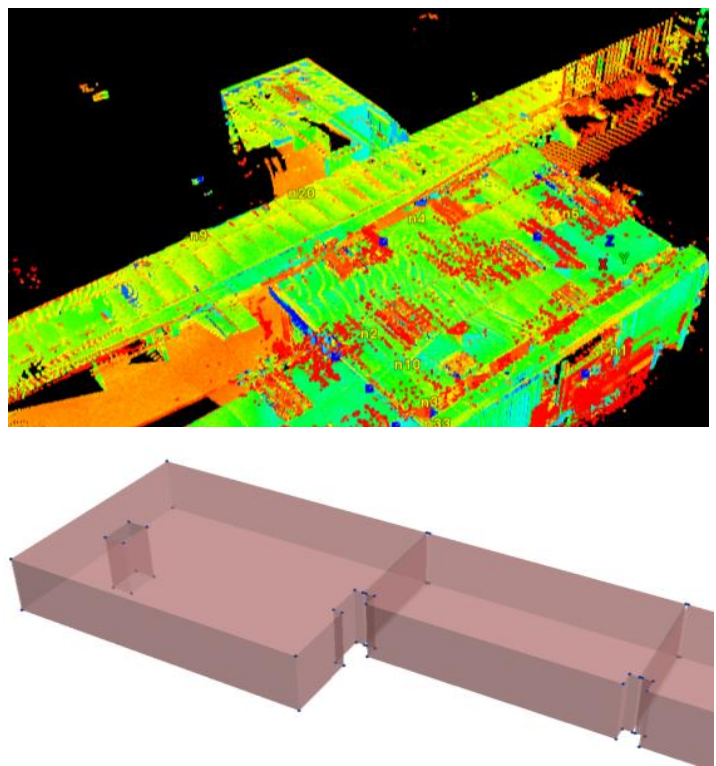

Figure 3. Point Cloud (above) to 3D model (below)

However, the model needs to register and it is designed as a base for various land registration practice in different countries (Oosterom et. al, 2006; Chong, 2006). Solution towards 3D cadastre registration could have with two common models and the models are Core Cadastral Domain Model (CCDM) and 
Hybrid Cadastre Data Model (Hassan et. al, 2008). These models have been used as a platform to suit with the Malaysian strata system. The administrative component is created to show the attributes for registered 3D cadastre object. The attributes shows the information as follows in table 1:

Table 1. Attribute for registered 3D cadastre object (Hassan, 2008).

\begin{tabular}{|c|c|c|c|}
\hline $\begin{array}{c}\text { Entity } \\
\text { Name }\end{array}$ & $\begin{array}{c}\text { Geometry } \\
\text { Type }\end{array}$ & Field Name & Key \\
\hline Owner & & Owner No & PK \\
\hline & & Name & \\
\hline & & IC_No & \\
\hline 3DParcel & Polygon & Owner_No & PK \\
\hline & & Geometry & \\
\hline & & Lot No. & FK \\
\hline LandParcel & Polygon & Lot No. & PK \\
\hline & & Geometry & \\
\hline
\end{tabular}

However, it was decided to transformation from conceptual model to database table, to better assess the issues involved identifiers generated by the system in addition to 'user identifiers', such as unique parcel identifier (UPI) (Zulkifle, 2014).

\subsection{XML and IndoorGML}

The actual encoding of the 3D Parcel (as part of the initial registration/survey plan) in the XML standard format based on the integration of LADM-3D and CityGML (OGC standard for 3D city objects based on GML (XML encoding) and this solution allows explicit links between a 3D cadastral (Vandysheva, 2011). IndoorGML puts emphasis on connectivity of spaces related to the navigability as one of the main use cases (Zlatanova, 2016). IndoorGML is based on two conceptual frameworks namely Structured Space Model (SSM) and Multi-Layered Space Model (MLSM).

\subsubsection{SSM}

The Structured Space Model defines the general layout of each space layer independent from the specific space model which it represents. Each layer is systematically subdivided into four segments (see Figure 4).

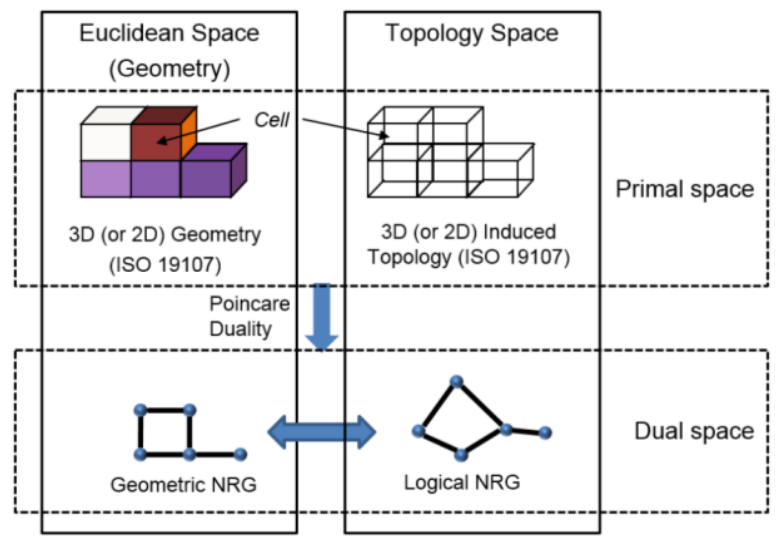

Figure 4. SSM concept (www.indoorgml.net)

This figure illustrates the structured space model that allows for the distinct separation of primal space from dual space on the one hand, and geometry and pure topology on the other hand. This structure forms the basis for the framework proposed indoor space model. The upper and the lower part of the figure follows the rules of ISO 19107 for modelling geometrical features of real world phenomena, but the transition from primal to dual space cannot be modelled or described via the ISO standard (Li, 2013).

And topological relationships in IndoorGML such as adjacency and connectivity are not defined by means of the topology in ISO 19107 but by explicit associations within the IndoorGML data model. In the Structured Space Model, topological relationships between 3D (or 2D) spatial objects are represented within topology space (i.e., the lower part of the figure).

By applying a duality transformation, the 3D cells in primal space are mapped to nodes (0D) in dual space. The topological adjacency relationships between $3 \mathrm{D}$ cells are transformed to edges (1D) linking pairs of nodes in dual space. Furthermore, the node of NRG is called state and the edge of NRG is called transition. The active state is represented by a node within the NRG and denotes the spatial area where the guided object is currently located.

Once the object moves into a topologically connected area, another node within the NRG and thus a new active state is reached. The edge connecting both nodes represents the event of this state transition. The NRG representing topological relationships among $3 \mathrm{D}$ spatial objects in topological space is a logical NRG, while the NRG embedded to Euclidean IR3 space is a geometric NRG.

\subsubsection{MLSM}

The concept of Structure Space model is further extended to Multi-Layered Space Model (MLSM). Multi-Layered Space Model provides an approach for combining multiple space structures for different interpretations and decomposition layers to support full indoor information services (Lee, 2014).

A same indoor space is often differently interpreted depending on application requirements as discussed above. It results in different decompositions of a same indoor space, and each decomposition results in a NRG. For example, the layers for topographic space layer, WIFI sensor space layer, and RFID sensor space form independent structured spaces and each layer results in three separate NRGs as depicted in Figure 5.

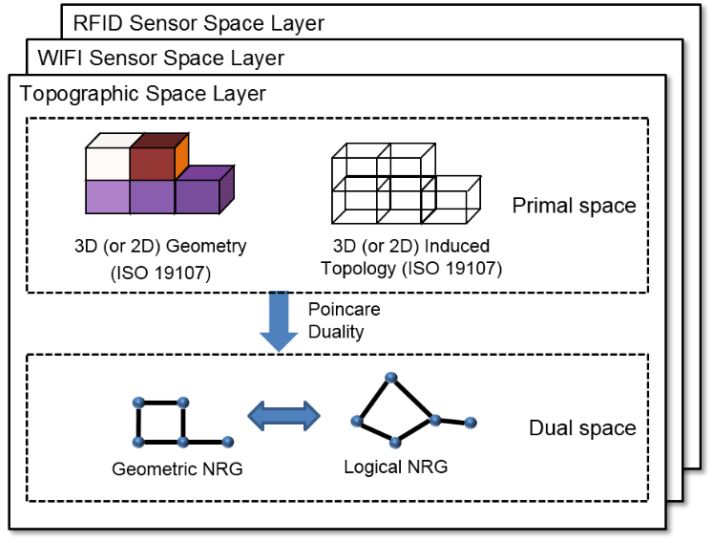

Figure 5. MLSM concept (www.indoorgml.net). 


\section{CONCLUSION AND FUTURE WORKS}

The approach of 3D modelling provides a new dimension for 3D strata. The legal, institutional and technical aspects of 3D geospatial database for cadastre provide the framework for the development and implementation. However, 3D data modelling is one of the elements for a successful 3D geospatial database. A standard data model is important to facilitate interaction between database i.e. spatial and non-spatial database. In this paper, we described current 2D strata and the issues towards 3D spatial strata registration. We anticipate extending this work by incorporating IndoorGML.

\section{REFERENCES}

Chong, C. S. (2006). Toward a 3D Cadastre in Malaysia - An Implementation Evaluation. Delft, Delft University of Technology: 110

Hassan, M. I., Ahmad-Nasruddin, M. H., Yaakop, I. A., \& Abdul-Rahman, A. (2008). An integrated 3D cadastre-Malaysia as an example. The International Archives of the Photogrammetry, Remote Sensing and Spatial Information Sciences, 37(B4), 121-26.

Isa, M.N., Chan, K. L., Hashim, M.N., Hassan, M.I., Idris, K.M and Abdul-Rahman, A., Malaysia. 3D Strata Modelling based on Indoor LiDAR Data (9476). FIG Congress: Enhancing the geospatial maturity of societies Istanbul, Turkey, May 6-11, 2018.

Lee, J., Li, K. J., Zlatanova, S., Kolbe, T. H., Nagel, C., \& Becker, T. (2014). OGC IndoorGML. Open Geospatial Consortium standard.

Li, K. J., \& Lee, J. Y. (2013). Basic concepts of indoor spatial information candidate standard IndoorGML and its applications. Journal of Korea Spatial Information Society, 21(3), 1-10.

Mohd. Noh, N., 2012. Development of Three-Dimensional (3D) Strata Database using ArcGIS Software. Project paper. Final year thesis for Bachelor of Geomatics Engineering. Universiti Teknologi Malaysia.

Nasorudin, N. N., Hassan, M. I., Zulkifli, N. A., \& Rahman, A. A. (2016). Geospatial Database for Strata Objects Based on Land Administration Domain Model (LADM). The International Archives of Photogrammetry, Remote Sensing and Spatial Information Sciences, 42, 329.

Pirounakis, N. G. (2013). Real Estate Economics: A Point-ToPoint Handbook. N. Y: Routledge

PKPUP Circular, Volume 1/2015.

\section{STA (1985). Strata Titles Act 1985.}

Vandysheva, N., Ivanov, A., Pakhomov, S., Spiering, B., Stoter, J. E., Zlatanova, S., \& Van Oosterom, P. J. (2011). Design of the 3D Cadastre Model and Development of the Prototype in the Russian Federation. In Proceedings 2nd International
Workshop on 3D Cadastres, Delft, The Netherlands, 16-18 November, 2011. International Federation of Surveyors (FIG).

Oosterom, P., Lemmen, C., Ingvarsson, T., van der Molen, P., Ploeger, H., Quak, W., \& Zevenbergen, J. (2006). The core cadastral domain model. Computers, Environment and Urban Systems, 30(5), 627-660.

Zlatanova, S., Li, K. J., Lemmen, C., \& Van Oosterom, P. J. M. (2016). Indoor abstract spaces: linking IndoorGML and LADM. In 5th International FIG 3D Cadastre Workshop. International Federation of Surveyors (FIG).

Zulkifli, N. A., Abdul Rahman, A., Jamil, H., Teng, C. H., Tan, L. C., Looi, K. S., ... \& Van Oosterom, P. J. M. (2014). Towards Malaysian LADM country profile for $2 \mathrm{D}$ and $3 \mathrm{D}$ cadastral registration system. In Proceedings of the 25th FIG Congress: Engaging the challenges, enhancing the relevance, Kuala Lumpur, Malaysia, June 16-21, 2014. FIG International Federation of Surveyors.

Zulkifli, N.A., 2014. Adoption of Land Administration Domain Model for Land Administration In Malaysia. MSc Thesis (Geoinformation). Universiti Teknologi Malaysia.

Revised August 2018 